\title{
A cash flow-based approach for assessing expansion options stemming from project modularity
}

\author{
Franco Caron* \\ Department of Management, Economics and Industrial Engineering, \\ Politecnico di Milano, \\ Piazza Leonardo da Vinci 32, 20133 Milan, Italy \\ Fax: +39-02-2399-4067 \\ E-mail: franco.caron@polimi.it \\ *Corresponding author
}

\section{Monia Comandulli}

\author{
ABB, Process Automation Division, \\ Via Luciano Lama 33, 20099 Sesto San Giovanni (MI), Italy \\ E-mail: monia.comandulli@it.abb.com
}

\begin{abstract}
Investment projects in the electricity production industry face a dynamic and complex context. Project's modularity, through the breakdown of the project output into a set of small identical independent units, enables a stepwise investment policy and a partial self-financing of the project, so improving project's flexibility. As a consequence, the construction phase may be described as a sequence of expansion options, each option allowing for deciding if and when to build the next production unit. Firstly, this paper proposes a model of the project cash flow aiming at evaluating and comparing alternative configurations of a production plant, considering both the construction and operation phases. Secondly, an expanded net present value model, based on Monte Carlo simulation, has been developed in order to estimate the value for the project of the expansion options stemming from project's modularity. The model has been applied to a case concerning a III+ generation modular nuclear power plant.
\end{abstract}

Keywords: large engineering projects; modularity; real option analysis; ROA; Monte Carlo simulation; modular nuclear plants; expansion options; project cash flow.

Biographical notes: Franco Caron is an Associate Professor with the Management, Economics and Industrial Engineering Department at Politecnico di Milano. He is in charge of the course of 'Management of large engineering projects' both in the Systems Engineering and Industrial Engineering Programmes. He is also in charge of the course of Project Risk Analysis and Management both in the Executive Master in Engineering and Contracting (EMEC) - developed jointly by MIP (Politecnico MBA Programme) and ANIMP (Italian National Association of Engineering and Contracting Companies) - and Master in Strategic Project Management European - 
developed jointly by MIP-Politecnico di Milano, Heriot Watt University Edimburgh and UMEA University, Sweden. Currently, his specific research interests concern: project risk management, proposal management, portfolio management and financial risk in project development.

Monia Comandulli graduated at Politecnico di Milano in Management Engineering, with specialisation in Major Projects Management and Finance. She is currently working at ABB, Process Automation Division as a Process Analyst. She is in charge as the Project Manager of the implementation of business process reengineering and continuous improvement projects. She also worked as a Project Manager Associate on oil and gas projects. Currently, her specific research interests concern financial risk in project development.

\section{Introduction}

The traditional approach to project management focuses on the stability of the project plan as a critical success factor, but the increasing level of complexity and uncertainty in the business context requires a high level of adaptability to emerging changes. Project risk management and project flexibility are typical responses to uncertainty and complexity: the former typically addresses identified risks, the latter develops the ability to react in the face of unanticipated events or conditions affecting the project, providing options to change the project's plan.

The set of measures taken to deal with anticipated risks (so improving project's robustness) and unanticipated events (so improving project's flexibility) are at the core of project strategy (Arrto et al., 2008, 2009; Floricel and Miller, 2001; Morris and Jamieson, 2005; Kolltveit et al., 2004).

Focusing on flexibility, a distinction can be made between product flexibility and project flexibility (Olsson, 2006): product flexibility tends to guarantee adaptability of the product to a changing demand, project flexibility tends to adapt the project plan to emerging situations. Both product and project flexibility aim at avoiding disruptive scope changes during project development (Olsson, 2008).

The need for project flexibility derives from the fact that important decisions affecting the project development are generally subject to incomplete information and emerging events change the assumptions adopted at the early stage of project planning. The main requirements in order to achieve a high level of flexibility in the decision-making process are:

- decisions should be sufficiently 'robust' in order to minimise changes in previous decisions due to subsequent decisions or, in any case, to modify previous decisions at minimum cost

- decisions should be postponed as long as the value of information remains high, in order to minimise the gap between the knowledge necessary to take the decision and the available knowledge

- decisions should be taken considering the lead time necessary to implement the corresponding actions. 
Olsson (2006) identifies three general strategies to exploit flexibility in the decision-making process: late locking, stepwise locking and contingency planning.

The first strategy implies an iterative exploration of the project alternatives during the front end phase; once the project is locked the execution phase requires the stability of the project plan. The second one is based on a sequence of 'decision gates' allowing for a progressive definition of project's plan. The third one identifies a set of alternative plans that can be activated if needed.

Large engineering projects, like for instance, power plants realisation, represent a typical example of projects affected by a high level of complexity and uncertainty. In large engineering projects, project effectiveness is a composite measure, combining economic performance, technical functionality, social acceptability, environmental acceptability, political legitimacy and economic development (Miller and Lessard, 2000). Large engineering projects are shaped progressively from an initial concept by the interaction of stakeholders (Arrto et al., 2009; Miller and Lessard, 2000, 2001). As a result, projects interact with their complex and uncertain environment and adapt to the ongoing changes as strategic entities (Arrto et al., 2008). In general, the available approaches aiming to improve project flexibility include: modularity, redundancy, real options, contingency planning. In particular, modularity (Hellstrom and Wikstrom, 2005) allows for the breakdown of the project output into a set of identical sub-units and represents a way of dealing with complexity as each sub-unit may be built and managed independently. Advantages deriving from modularity are related to both project phases:

- $\quad$ project execution, e.g., in terms of stepwise investment

- $\quad$ system operation, e.g., in terms of system availability.

Focusing on project execution, a stepwise investment policy corresponds to a sequence of expansion options, since each investment decision may be taken or deferred based on the expected profitability. Among the different types of real options (technology change, extended life cycle, etc.), expandability, i.e., the company's ability to add capacity in an existing plant, is akin to a call option.

In financial terms, a call option, also known as 'buy option', is a contract between two parties, the buyer and the seller, in which the buyer of the option has the right, but not the obligation, to buy an agreed quantity of a particular commodity or financial asset (the underlying asset) from the seller of the option at a specified time in the future (the expiration date) for a certain price (the strike price). The seller (or 'writer') is obligated to sell the commodity or financial asset should the buyer so decide. The buyer pays a fee (called a premium) for this right. On the other side, a put option (usually just known as a 'sell option') is a financial contract between two parties, the writer (seller) and the buyer of the option. The buyer has the right to sell the underlying asset to the seller of the option for a specified price (the strike price) during a specified period of time. If the option buyer exercises his right, the seller is obligated to buy the underlying asset from him at the agreed upon strike price, regardless of the current market price. In exchange for having this option, the buyer pays the seller or option writer a fee (the option premium) (O’Sullivan, 2003).

Since in large engineering projects investments are usually irreversible, the expandability option may be exploited, since the opportunity to postpone financial commitment in order to learn more about the future increases the likelihood of project success (Dixit and Pindyck, 2000). 
The paper aims at developing a cash flow-based model for estimating the value shift for a project adopting a modular approach exploited in terms of a sequence of expansion options during the project execution phase. The model has been applied to an industrial case related to the realisation of a modular nuclear power plant.

At present, III generation nuclear reactors are available, while IV generation models are still under development and will not be on the market until 2030. III + generation plants, be they large reactors (LRs) or small medium reactors (SMR) present interesting development prospects, the former offering economies of scale, while, by virtue of the modularity of the investment, the much smaller SMRs can take advantage of economies of learning, reduced financial requirements, and greater flexibility in responding to market trends. Indeed, in addition to operational advantages in terms of availability and continuity of energy supply, plant's modularity guarantees a high level of project flexibility, allowing for the possibility of deciding during the course of the project if and when to expand plant's capacity, i.e., if and when to build another reactor identical to the one(s) already in operation. This means that during the construction phase, there is a sequence of decision-making gates when management has to decide whether or not to invest in another module. With the development of the project, these decision-making gates are associated to an increasing level of information, which if appropriately exploited can result in an increase in the overall value of the project. In particular, the possibility to put off the investment in subsequent modules, if expected market trends are not favourable, is like an US call option. The majority of options are either European or US style options. The key difference between US and European options relates to when the options can be exercised: a European option may be exercised only at the expiry date of the option, i.e., at a single pre-defined point in time; an US option, on the other hand, may be exercised at any time before the expiry date (Kodukula and Papudesu, 2006).

The flexibility associated to modular SMRs is an extremely interesting characteristic for investors in an exceptionally uncertain and dynamic market like the electricity production industry. Furthermore, during plant construction, there are usually only outgoing cash flows. In contrast, during construction of a modular plant involving several modules, outgoing cash flows may be accompanied by incoming flows deriving from modules that have been completed and become operational.

This paper aims at estimating the value deriving for the project from the flexibility linked to plant's modularity. Firstly, the paper proposes a general model of the project cash flow, made up by three sub-models related to construction phase, operation phase and trend over time of the price of electrical energy, respectively. The model covers the overall project life cycle and allows for a comparison of alternative investment projects in the electricity production industry. Secondly, drawing on the above cash flow model, an expanded net present value (ENPV) model, based on Monte Carlo simulation, has been developed for the assessment of the value of the expansion options that project's modularity may offer to a power plant construction project.

Section 2 introduces the different approaches available in a real option analysis (ROA) framework, explaining the reasons for the choice of the ENPV approach, implemented through Monte Carlo simulation, as a suitable tool for the assessment of the expansion options stemming from project's modularity. Section 3 introduces the general cash flow model, used to assess investment projects in the electricity production industry, considering both construction and operation phases. In Section 4, an ENPV model has been developed in order to estimate the value of the expansion options deriving from project's modularity, through the comparison between a modular configuration of the 
production plant without expansion options and a modular configuration with expansion options. In Section 5, the ENPV model is applied to an industrial case concerning a III + generation modular nuclear power plant. Section 6 summarises and analyses the results obtained.

\section{Real options analysis}

The choice to proceed in the construction of an energy production plant represents a capital budgeting project. One of the most popular valuation method used to estimate the potential for investment is the discounted cash flow (DCF). DCF analysis uses future free cash flow projections and discounts them to arrive at the net present value (NPV), which can be compared with the current investment cost, so that the higher the value assessed with DCF the higher the expected return on investment (Damodaran, 2002).

A particular approach to DCF, often applied to the comparison of alternative technologies for the production of electrical energy, is the levelised cost valuation model, which, assuming a null profit, allows us to establish the best technological alternative by calculating the levelised unit electricity cost (LUEC) of each alternative (Feretic and Tomsic, 2005; Fraser, 2003). This methodology presents some limitations, associated mainly to the difficulties in effectively incorporating uncertainty in the LUEC. As a result, in the following the DCF model has been preferred which, when integrated with Monte Carlo simulation, can easily take account of uncertainty (Rode et al., 2001; Roques et al., 2006).

DCF alone, however, is not able to assess the contribution of project flexibility, especially the contribution to project value deriving from real options, e.g., from expandability (Dixit and Pindyck, 1994; McDonald and Siegel, 1984; Myers, 1984; Trigeorgis, 1995). There are two principal approaches to assess projects subject to uncertainty in which project flexibility plays an important role:

- decision analysis (in particular decision tree analysis, DTA)

- $R O A$.

ROA derives from the option pricing approach (Black and Scholes, 1973; Merton, 1973; Myers, 1977, 1984; Ross, 1978; Kester, 1984; Smith and McCardle, 1998). The first procedure is more general than the second (Smith and McCardle, 1998) and allows uncertainty to be introduced by defining a probability for each output (i.e., for each payoff associated to the terminal nodes), but, since it is an exhaustive methodology, the size of the problem must be limited (Kodukula and Papudesu, 2006). In contrast, ROA is more easily adaptable to large and complex situations, but requires a different assessment rule than traditional DCF: ENPV (Trigeorgis, 1995). This approach enriches the NPV deriving from the application of traditional DCF with the value of the options related to the management's possible influence on the project development. ROA does not replace DCF, but represents an extension (Kodukula and Papudesu, 2006), since, when a project presents no option, the DCF and the ROA coincide. In the following, ROA will be implemented through an ENPV approach in order to assess the expansion options deriving from project's modularity.

ROA considers real options as a strategic leverage in capital investment decisions, since it takes into consideration the increasing level of information made available as the 
project progresses, so reducing the uncertainty level affecting the decision-making process (Mun, 2002).

Figure 1 Possible approaches to assess options and related application fields

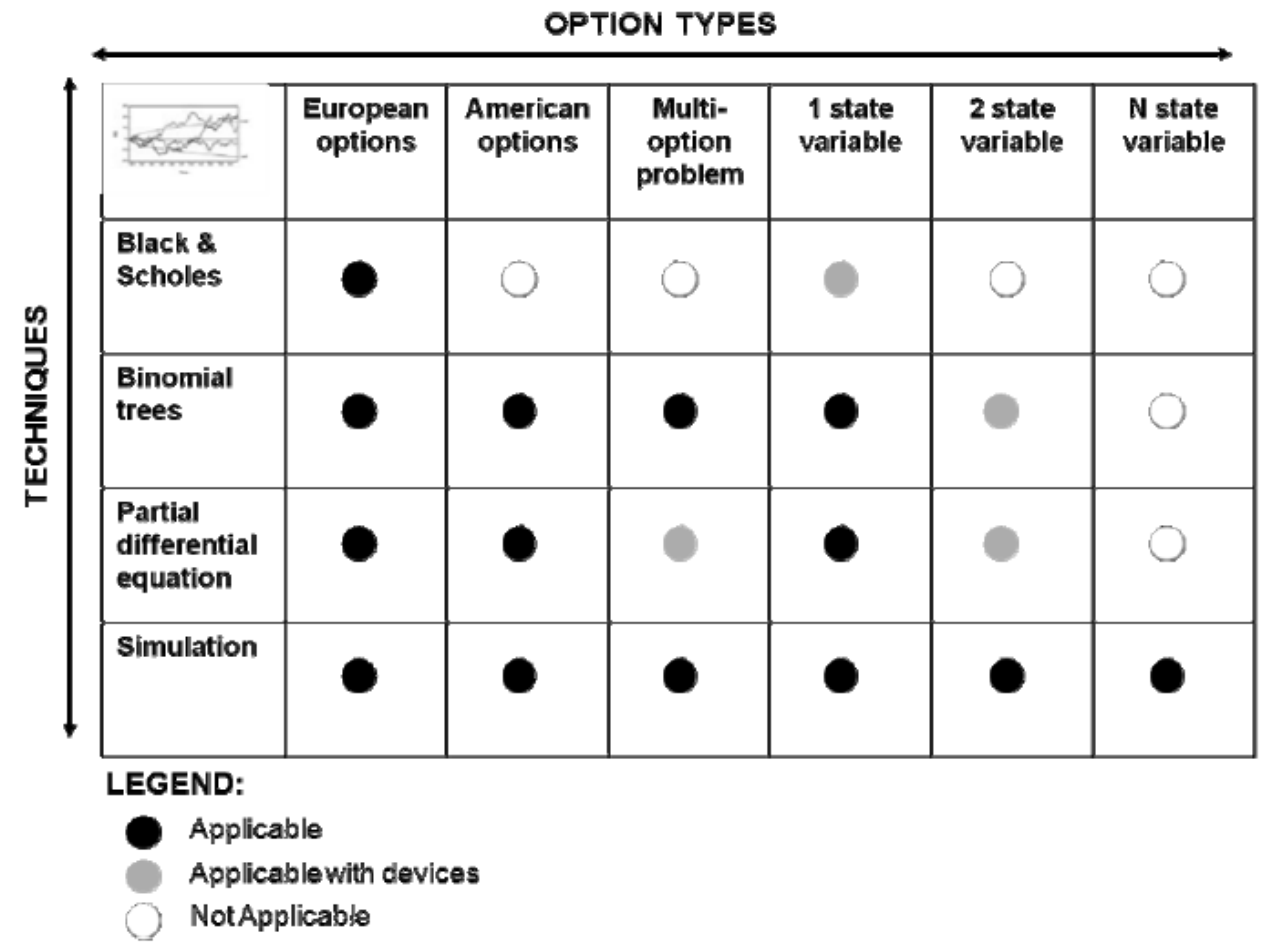

Use of ROA is appropriate when management has ample room for intervention against a high level of uncertainty. Moreover, the contribution provided by ROA is particularly significant in those situations in which the traditional NPV tends to negligible values, since the option value may assume a decisive role in the decision-making process. Taking into account ROA, managers are encouraged to think about the project in a proactive and creative way, and consider how project value can be increased through flexibility (Brabazon, 1999; Browman and Moskowitz, 2001).

ROA requires the use of one of the following methods:

- partial differential equations (PDE)

- lattices

- simulation.

However, a PDE approach may not provide a closed analytical solution (Schwartz and Trigeorgis, 2004), is not suitable for the assessment of US options and does not aid the introduction of uncertainty (Dixit and Pindyck, 2000; Kodukula and Papudesu, 2006). The best known PDE approach is based on the Black-Scholes formula (Black and Scholes, 1973). Lattices are more flexible than PDE, but are difficult to control with a large number of stochastic variables (Copeland and Antikarov, 2001; Smith, 2005; Trigeorgis, 1993). The most flexible tool, since it does not need any unnecessary 
simplifying assumption, and consequently the one used in the present study, is Monte Carlo simulation (Cobb and Charnes, 2007; Kodukula and Papudesu, 2006) (see Figure 1). In the context of Monte Carlo simulation also the analysis of the US options may be developed, considering that the type of decision and the time of decision concerning each option have to be determined simultaneously (Barraquand and Martineau, 1995; Broadie and Detemple, 1997a, 1997b; Broadie and Glasserman, 1995, 2004; Grant et al., 1997; Longstaff and Schwartz, 2001; Tseng and Barz, 2002).

Drawing on various studies on the assessment of the value of modularity, particularly the work of Moel and Tufano (2000), and the literature dealing with the energy sector (Roques et al., 2006), above all nuclear energy (Boarin and Ricotti, 2010; Gollier et al., 2005) an ENPV model (see Section 4), implemented through Monte Carlo simulation, has been developed in order to assess expansion options deriving from a stepwise investment in the electrical energy sector.

\section{The model of the project cash flow}

The model of the project cash flow can be used to assess and compare alternative investment projects for electrical energy production, independently from technology used (be it nuclear or not) and configuration adopted (be it modular or not).

The model takes into account all the cash flows, deriving from construction and operation phases, calculates the operational free cash flow (OFCF) and determines the profitability of the investment. The model comprises three sub-models concerning respectively:

- the construction phase

- the operation phase

- the trend over time of the price of electrical energy.

The model places particular emphasis on the construction phase, during which plant's modularity may be exploited in terms of expansion options and management has an ample room for intervention, so needing a more detailed level of analysis. This is not the case during the operation phase, when external variables, in particular the electricity price, play a dominant role.

During the construction phase, cumulated expenditure is modelled with a flexible ' $\mathrm{S}$ ' curve, whose final values, total duration and total expenditure, can vary independently of each other, so creating situations in which just one or both parameters may deviate from the project baseline.

The curve's adaptability allows different types of delay in construction phase to be modelled. Overall, the various types of delay that the model can manage are as follows:

- A non-recoverable delay without additional expenditure. Such a delay increases the construction time, postponing operational cash in-flows, but does not cause any additional costs [see Figure 2(a)].

- A non-recoverable delay with additional expenditure. Such a delay increases the construction time, postponing operational cash in-flows, and causes additional costs [see Figure 2(c)]. 
- A recoverable delay. Such a delay does not increase the construction time, and therefore does not influence operational cash in-flows, but requires that more resources are put in place and the corresponding additional costs are spread over the remaining duration of construction [see Figure 2(b)].

Figure 2 Different types of delay during construction, (a) non-recoverable delay without additional expenditure (b) recoverable delay with additional expenditure

(c) non-recoverable delay with additional expenditure

\section{Cumulative Expenditure profile}

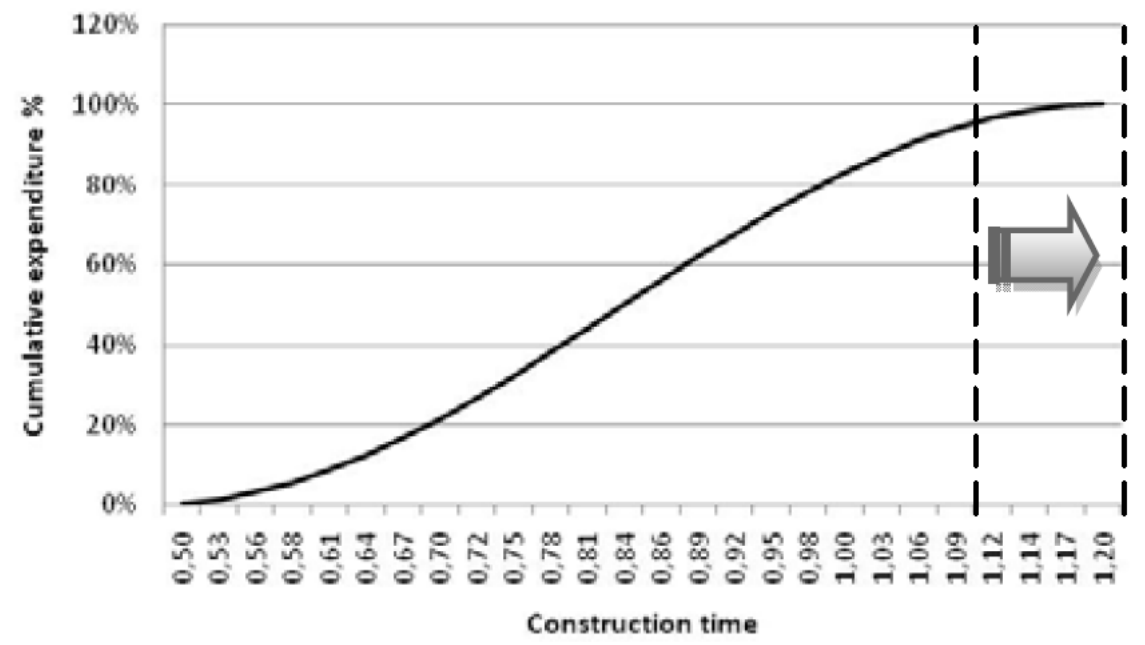

(a)

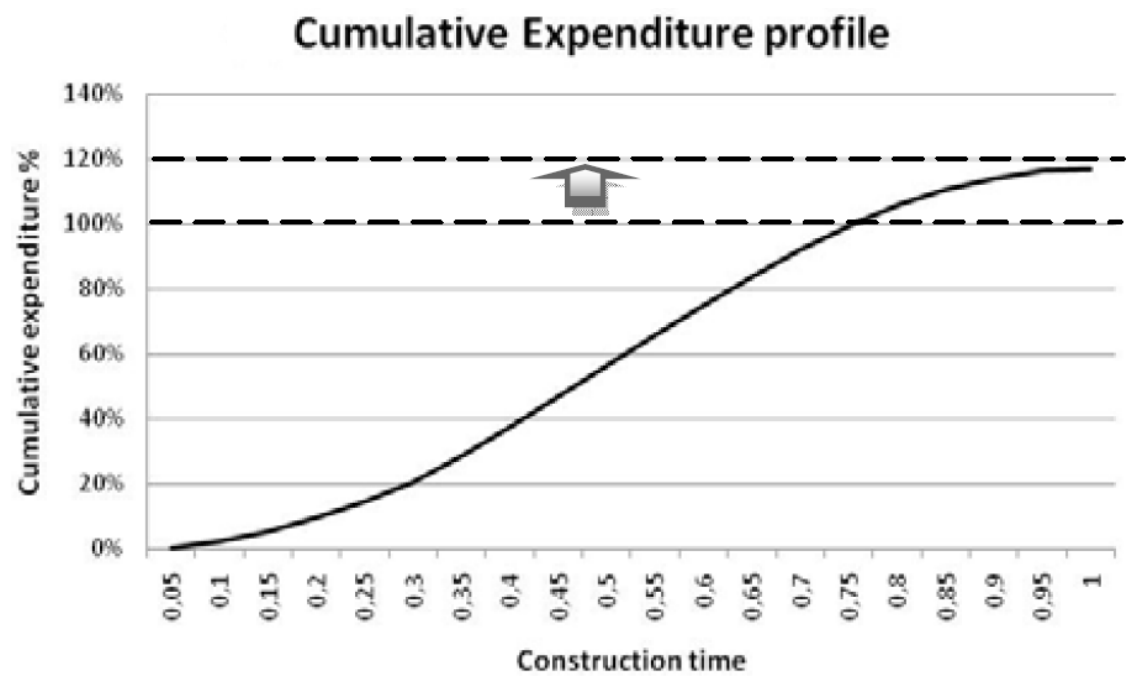

(b) 
Figure 2 Different types of delay during construction, (a) non-recoverable delay without additional expenditure (b) recoverable delay with additional expenditure

(c) non-recoverable delay with additional expenditure (continued)

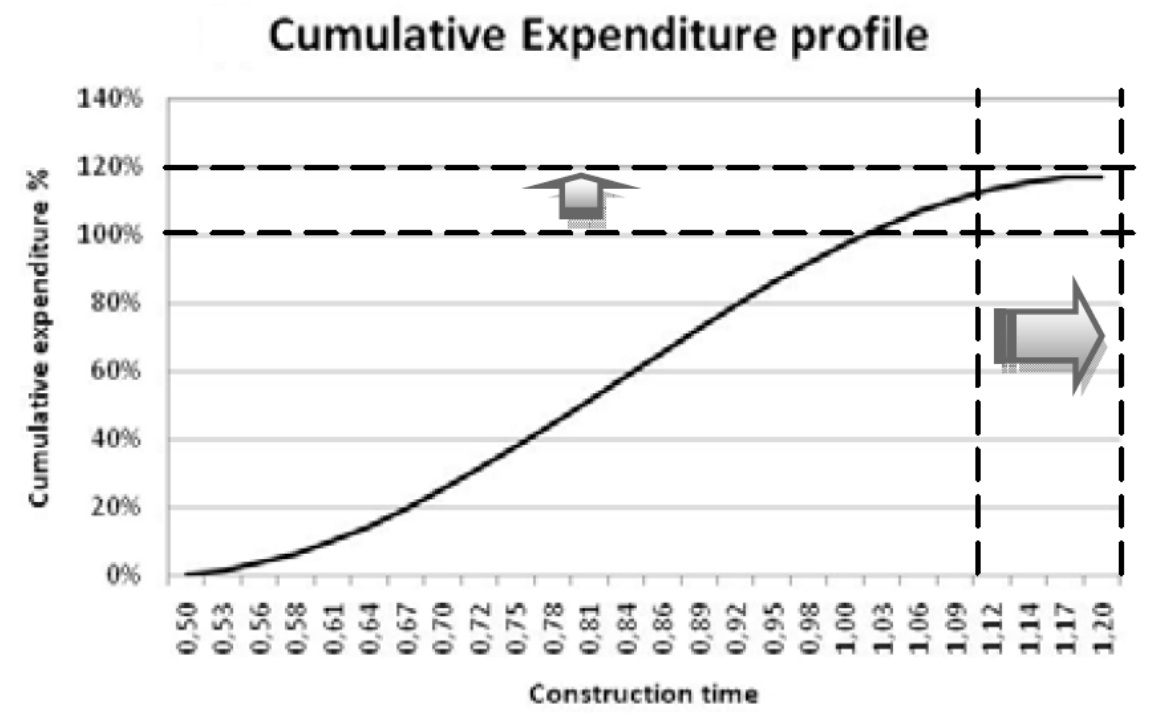

(c)

The model considers three sources of funding:

- equity

- debt

- $\quad$ self-financing.

Assumptions about the mix of equity and debt are adopted at the beginning of the simulation process in terms of the ratio between them. Debt is paid back when the plant comes into operation.

Self-financing is possible only for modular plants, as it exploits the cash inflows from previously constructed modules. Self-financing has a greater influence the longer the time lapse between the construction of the modules, and, in particular, has a greater impact on the last modules.

The model of the operation phase considers the different elements that determine the cash flow. Operational revenues depend on the quantity of electrical energy supplied to the network and are calculated considering both the capacity factor, a parameter which takes account of the plant's availability factor, and the load factor, related to the quantity of energy that can be transmitted to the electricity network. Operational costs increase over time in line with nominal inflation, which is a country-specific parameter. Account is also taken of the possibility that there is a plant breakdown during operation resulting in a temporary interruption of electricity production and an increase in costs determined by the necessary maintenance.

Finally, the analysis of the trend over time of the price of electrical energy is based on a 'mean reverting with jump diffusion' model, comprising the following three components (Blanco et al., 2001; Blanco and Soronow, 2001a, 2001b): 
1 geometric Brownian motion (GBM), which describes the volatility of the price of electrical energy around the equilibrium value

2 mean reversion, which describes the 'force' that tends to bring the price of electrical energy back to the equilibrium value after it moves

3 jump diffusion process, which describes the effect of unexpected and very large increases or decreases in the price of electrical energy.

In the case illustrated below, the parameters describing these three components (see Table 1) are derived from the historical trend of prices in a European country market.

The cash flow model, comprising the three sub-models related to construction, operations and electricity price trend respectively, allows to assess and compare alternative plant's configurations for electrical energy production; for instance, it allows a comparison of a nuclear LR with a set of modular SMR that offer the same overall capacity.

The general structure of the model is given in Figure 3.

Figure 3 Inputs and outputs of the model

\begin{tabular}{|c|c|c|}
\hline INPUT & MODELLO & OUTPUT \\
\hline 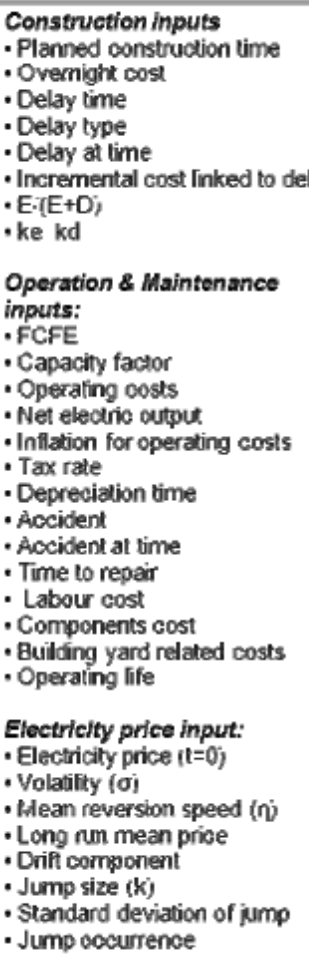 & DCF & $\begin{array}{l}\text { - NPy } \\
\text { - Total option value } \\
\text { - Self - financing } \\
\text { - Total investment } \\
\text {-. }\end{array}$ \\
\hline
\end{tabular}


Table 1 Parameters of the mean reverting with jump diffusion model

\begin{tabular}{|c|c|c|}
\hline Parameters & Definition & Value \\
\hline $\mathrm{P}(\mathrm{t}=0)$ & Electricity price at initial time $\mathrm{t}=0$ & $99.07[€ / \mathrm{MWh}]$ \\
\hline Volatility & Expected price variability over time & $14.31 \%$ \\
\hline Mean reversion speed & $\begin{array}{l}\text { Speed at which prices revert to equilibrium } \\
\text { value }\end{array}$ & $51.13 \%$ \\
\hline $\begin{array}{l}\text { Mean reversion level or } \\
\text { long run mean price }\end{array}$ & Equilibrium price & $88.81[€ / \mathrm{MWh}]$ \\
\hline Drift component & Electrical energy price drift & $0.65[€ /$ quarter $]$ \\
\hline Jump size & $\begin{array}{l}\text { Maximum expected size of jumps, expressed } \\
\text { in percentage terms of the price recorded in } \\
\text { previous period }\end{array}$ & $40 \%$ \\
\hline Standard deviation of jump & Dispersion of jumps around their mean value & $10 \%$ \\
\hline Jump occurrence & $\begin{array}{l}\text { Average jumps frequency over a predefined } \\
\text { period of time }\end{array}$ & $\begin{array}{c}0.02 \\
\text { [jumps/quarter] }\end{array}$ \\
\hline
\end{tabular}

\section{The ENPV model}

The cash flow model has been used to develop an ENPV model, in order to assess the value of the expansion options made possible by the modular configuration of the plant. The ENPV model helps to decide when, and whether, to expand the production capacity during the construction phase. In order to strictly isolate the value of the expansion options during the construction phase, a benchmark configuration is needed, characterised by the same operational features of the modular configuration in terms of capacity, availability, service continuity, etc. but without the expansion options. So, the ENPV model requires the comparison between two alternative configurations of the plant:

- a modular configuration without expansion options, i.e., the benchmark configuration

- a modular configuration with expansion options, i.e., the actual configuration.

At each simulation iteration, the value of the expansion options will be derived by comparing the NPV of the investment with expansion options and the NPV of the same investment without expansion options (Mason and Merton, 1985).

The first configuration, i.e., modular without expansion options, representing the benchmark against which the value of modularity in terms of expansion options is measured, is given by a set of modules strictly built in series without any time lapse between the end of the construction of one module and the beginning of the next, i.e., in a staggered stand alone mode. It is assumed that in this configuration management has no room for intervention because the construction strategy is completely frozen since the beginning of the project, allowing to imitate, in practice, a monolithic configuration, i.e., a non-modular configuration. 
The second configuration, i.e., the modular configuration with expansion options, after the start of the construction of the first module generates the option to invest in the second module. In the same way, when each module has been constructed, the management can decide whether to increase the plant's capacity or not.

Each simulation iteration provides an estimate of the overall value of the expansion options offered by project's modularity. For each simulation iteration ('level 0 ' iterations), the construction of the first module is simulated starting from the beginning of the planning horizon, and the trend of the electricity price during the overall life cycle of the plant is forecasted. Then, after the completion of the first module, the first expansion option is considered and a set of sub-iterations ('level 1' sub-iterations) is carried out in order to determine if and when to proceed with the construction of the second module.

It should be noted that at each simulation iteration ('level 0 ' iterations), the decision-making process concerning each expansion option involves all the subsequent modules required to reach the planned capacity. Considering, for instance, a sequence of n possible expansion options, at each 'level i' sub-iteration concerning the preceding expansion option corresponds a set of 'level $\mathrm{i}+1$ ' sub-iterations concerning the subsequent expansion option.

In this way, at each 'level 0' simulation iteration, all the modules required to reach the planned capacity are progressively added, unless the project is stopped at a lower capacity level, if required profitability is not guaranteed. It should be noted that this approach follows the actual decision-making process adding one module at time (see Figure 4).

Figure 4 Simulation process considering a single expansion option

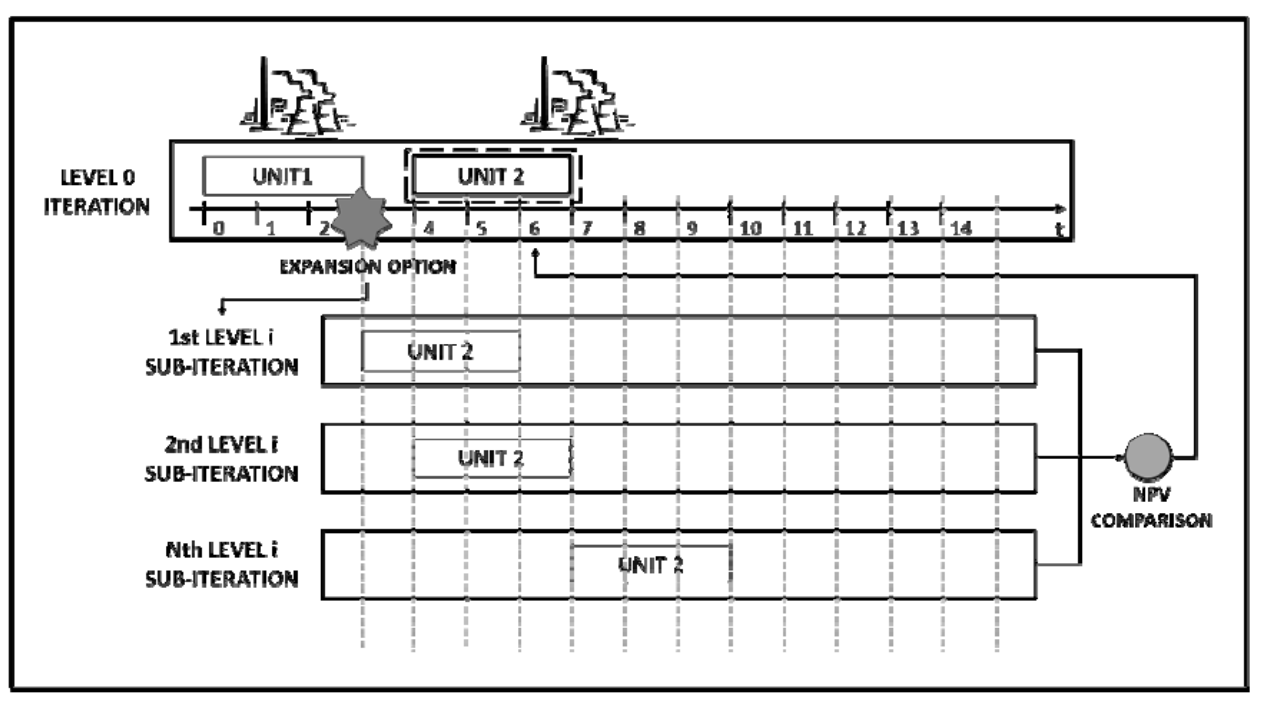

For each alternative configuration considered, the model explores all the possible construction strategies in terms of if and when exploiting each available option and calculates for each strategy the corresponding NPV; providing the NPV is positive, the strategy that gives the largest NPV is the one that is giving the greatest value to the project. Note that this NPV value represents a kind of upper limit: the proportion of this value that can be effectively harnessed depends on management's ability to analyse the 
context and exploit the greater information that becomes available as the project progresses.

At the end of each 'level 0' iteration, a comparison may be carried out, in terms of NPV values, between the alternatives considered, i.e., between the modular configuration with expansion options and the benchmark corresponding to the modular configuration without expansion options. In this way, an estimate of the maximum value for the sequence of expansion options offered by the project modularity is obtained. Events generated during each simulation iteration (construction delay, equipment breakdown, etc.) affect all the alternatives considered in a similar way.

\section{A nuclear power plant case}

The ENPV model proposed in the previous section has been applied to the case of a project concerning the construction of a modular nuclear power plant, consisting of three SMRs. A comparison has been carried out between two alternative configurations of the plant: a modular configuration without expansion options, i.e., the benchmark configuration, and a modular configuration with expansion options, i.e., the actual configuration. Below, the main assumptions adopted for the variables of the ENPV model are described.

Construction of the first module starts at the beginning of the planning horizon, while the construction strategy adopted for the subsequent SMR units, depending on the foreseen trend of the electricity price, assumes that the individual modules are constructed in series, so exploiting their operational autonomy (i.e., in a standalone mode). Specifically, it has been assumed that there is no time overlap between the construction of the modules, i.e., a module can only be built if the previous module has been completed. As exploitation of modularity in terms of expansion options means that the stepwise investment can be distributed over time, there may be a certain time lapse following completion of the previous module before management may decide to build the next reactor.

Each single SMR can be built in about three years. Therefore, by using the construction strategy illustrated above, the overall production capacity is made available gradually. Given the strong focus on the construction phase, the unit time period considered in the model is three months.

The single SMR may have different overnight costs. In particular, it is necessary to consider that SMRs cannot benefit from the traditional economies of scale, but can take advantage of the economies of learning that derive from the construction of different modules in the same time and place, but also from the possible simultaneous construction of individual units at different sites. The learning effect is due to the scalable nature of the investments in SMRs and results in increasing efficiency and decreasing duration of the construction phase due to the experience acquired both by subcontractors and equipment suppliers (Miller, 2005). A reduction in the overall cost of construction of the plant can therefore be obtained as far as the number of modules increases. The assumed loss of economies of learning (and, consequently, the increase in the overnight cost) is linearly proportional to the time lapse between the completion of one unit and the start of the next, taking into account the number of years requested in order for all economies of learning to be lost (about ten years). 
The main cost driver of the overnight cost of the plant is represented by the electricity price. Along each simulation iteration, the overnight cost is calculated at each quarter as a function of the foreseen electricity price; the ratio between the variation in the price of electrical energy and the variation in the overnight cost of the plant is defined through a factor which considers both the weight of electrical energy in determining the price of materials and the incidence of the latter on the total overnight cost, respectively. A delay of three months has been introduced between the variations in the price of energy and the corresponding variations of the overnight cost of the plant. The overnight cost for each SMR is given from the value corresponding to the quarter in which construction begins, since most of the costs are committed in the early phase of the project.

The model assumes an operation phase of about 40 years. During this time, at each quarter, the price of electrical energy follows the trend of the 'mean reverting with jump diffusion' model. With regards the capacity factor, a constant load factor of $100 \%$ is assumed, as nuclear power stations are base-load plants. Consequently, reactor performance depends exclusively on the availability factor, which is taken as constant throughout the lifecycle of the plant.

The operational costs include the following items: fuel cost, operation and maintenance cost, decommissioning and decontamination (D\&D) sinking fund, and repair costs of any fault during the operating period. All operational costs increase with annual inflation. The D\&D sinking fund is taken as $20 \%$ of the construction cost, and therefore varies with the overnight cost.

The model considers just one type of major fault, e.g., a steam generator tube rupture (SGTR), and assumes it can occur only once in the lifetime of a power station. It is assumed that a possible breakdown at a given time would affect just one of the operating modules. Indeed, a modular plant, if it includes more than one unit, can guarantee a continuous supply of electrical energy to the distribution network, because even if a module is shut down as a result of a breakdown, the others can continue to operate, as they are constructed as stand-alone units. The overall result is that, despite the breakdown, a modular plant can nevertheless exploit at least part of its generating capacity. Repair costs fall in the same quarter in which the fault occurs.

The main assumptions used in applying the ENPV model to the case under examination can be summarised as follows:

- $\quad$ The project without expansion options used as a benchmark consists of three modules built in series and completely identical to the modules of the project with expansion options; the construction of the first module starts at the beginning of the planning horizon; the subsequent modules are built in series without any time lapse between them.

- The investment exploiting the sequence of expansion options comprises three modules, of which the first is again constructed at the beginning of the planning horizon; therefore, this plant's configuration has two options for expansion, linked to the second and the third modules respectively; the first option always exists, as the first reactor will be constructed regardless of the expected NPV, while the option involving the third module only exists if the second module is built.

- The lifetime of each expansion option is taken to be ten years; i.e., once a module has been completed, there is a ten years period during which the investment in the subsequent module can be postponed or even cancelled; during this period there is a linear loss over time in the economies of learning. 
In the simulation process, the overall time horizon may vary from iteration to iteration, depending on construction delays, on how many modules are built, and on the time lapse between the end of the construction of one module and the start of the next.

Table 2 and Table 3 summarise the inputs ant the outputs of the model respectively.

Table 2 Inputs to the model and corresponding values

\begin{tabular}{|c|c|c|}
\hline \multicolumn{3}{|c|}{ Deterministic inputs } \\
\hline \multicolumn{2}{|l|}{ Input } & Value \\
\hline \multicolumn{2}{|c|}{ Single unit net electric output } & $300 \mathrm{MWe}$ \\
\hline \multicolumn{2}{|c|}{ Single unit construction time } & 3 years \\
\hline \multicolumn{2}{|c|}{ Labour cost/overnight cost } & $40 \%$ \\
\hline \multicolumn{2}{|c|}{ Building yard related cost/overnight cost } & $15 \%$ \\
\hline \multicolumn{2}{|c|}{ First unit cost saving factor } & 1,40 \\
\hline \multicolumn{2}{|c|}{ Second unit cost saving factor } & 1,20 \\
\hline \multicolumn{2}{|c|}{ Third unit cost saving factor } & 1,13 \\
\hline \multicolumn{2}{|l|}{ Steam generator cost } & $19.23 \mathrm{mln} €$ \\
\hline \multicolumn{2}{|c|}{ Electrical energy influence on material cost } & $50 \%$ \\
\hline \multicolumn{2}{|c|}{ Material influence on overnight cost } & $48 \%$ \\
\hline \multicolumn{2}{|l|}{ Starting overnight cost } & $2,500 € / \mathrm{kWe}$ \\
\hline \multicolumn{3}{|c|}{ Stochastic inputs } \\
\hline Input & Distribution & Distribution's parameters \\
\hline Tax rate & Uniform & Min value $32 \%$, max value $38 \%$ \\
\hline $\begin{array}{l}\text { Inflation for operating } \\
\text { cost }\end{array}$ & Triangular & $\begin{array}{l}\text { Min value } 1,5 \% \text {, max value } 4 \% \text {, most likely } \\
\text { value } 3 \%\end{array}$ \\
\hline $\mathrm{kd}$ & Triangular & $\begin{array}{l}\text { Min value } 5 \% \text {, max value } 13 \% \text {, most likely value } \\
8 \%\end{array}$ \\
\hline ke & Uniform & Min value $12 \%$, max value $15 \%$ \\
\hline $\mathrm{E} /(\mathrm{E}+\mathrm{D})$ & Triangular & $\begin{array}{l}\text { Min value } 30 \% \text {, max value } 60 \% \text {, most likely } \\
\text { value } 50 \%\end{array}$ \\
\hline Availability factor & Triangular & $\begin{array}{l}\text { Min value } 90 \% \text {, max value } 100 \% \text {, most likely } \\
\text { value } 95 \%\end{array}$ \\
\hline Delay time & Uniform & Min value 1 quarter, max value 4 years \\
\hline Delay in quarter \# & Uniform & Min value $32 \%$, max value $38 \%$ \\
\hline O\&M cost & & \\
\hline Fuel cost & Uniform & Min value 6,3 , max value $7,7 € / \mathrm{MWh}$ \\
\hline Operating cost & Uniform & Min value 5,4, max value $6,6 € / \mathrm{MWh}$ \\
\hline D\&D sinking fund & Uniform & Min value 1,8, max value $2,2 € / \mathrm{MWh}$ \\
\hline Depreciation & Triangular & $\begin{array}{l}\text { Min value } 13, \text { max value } 20, \text { most likely value } \\
15 \text { years }\end{array}$ \\
\hline Accident & Histogram & Probability of accident $10^{-3}$ per year \\
\hline SG time to repair & Uniform & Min value 25 , max value 50 days \\
\hline $\begin{array}{l}\text { Linear loss of learning } \\
\text { economies in \# years }\end{array}$ & Triangular & $\begin{array}{l}\text { Min value } 4 \text {, max value } 7 \text {, most likely value } \\
6 \text { years }\end{array}$ \\
\hline
\end{tabular}


Table 2 Inputs to the model and corresponding values (continued)

\begin{tabular}{lll}
\hline \multicolumn{3}{c}{ Variable inputs sampled at each unit period during each iteration } \\
\hline Input & Estimation model & \multicolumn{1}{c}{ Model's parameters } \\
\hline Electricity price cost & $\begin{array}{l}\text { Mean reverting } \\
\text { with jump } \\
\text { diffusion }\end{array}$ & $\mathrm{P}(\mathrm{t}=0)=80 € / \mathrm{MWh}$ \\
& Volatility $=15 \%$ \\
& Mean reversion speed $=47 \%$ \\
& Long run mean price $=89 € / \mathrm{MWh}$ \\
& Drift $=0,5 € /$ quarter \\
& $\begin{array}{l}\text { Jump size }=35 \% \\
\text { Standard deviation of jump }=10 \%\end{array}$ \\
& $\begin{array}{l}\text { Jump occurrence }=0,02 \text { jump/year } \\
\text { Jump: binary variable that defines the presence } \\
\end{array}$ \\
& of jump according to the probability of \\
& occurrence $(\mathrm{P})$ as defined by 'Jump occurrence' \\
& jump $= \begin{cases}1, & P=6 \cdot 10^{-3} \\
0, & P=1-\left(6 \cdot 10^{-3}\right)\end{cases}$ \\
\hline
\end{tabular}

Table 3 Outputs from the model

\begin{tabular}{|c|c|}
\hline Output & Description \\
\hline Total value of project & NPV of the modular plant with expansion options \\
\hline First unit NPV & NPV of the first unit of modular plant with expansion options \\
\hline Second unit NPV & $\begin{array}{l}\text { NPV of the second unit of the modular plant with expansion } \\
\text { options }\end{array}$ \\
\hline Third unit NPV & $\begin{array}{l}\text { NPV of the third unit of the modular plant with expansion } \\
\text { options }\end{array}$ \\
\hline $\begin{array}{l}\text { NPV of modular expansion } \\
\text { options }\end{array}$ & $\begin{array}{l}\text { plant without NPV of modular plant without expansion } \\
\text { options }\end{array}$ \\
\hline $\begin{array}{l}\text { Second of modular without } \\
\text { expansion options }\end{array}$ & NPV of modular plant without expansion options \\
\hline $\begin{array}{l}\text { Third unit NPV without } \\
\text { expansion options }\end{array}$ & NPV of the third unit of the plant without expansion options \\
\hline Total investment & Overall investment to build the plant \\
\hline Total self-financing value & $\begin{array}{l}\text { Amount of the overall investment financed through the cash } \\
\text { flow generated by early deployed units }\end{array}$ \\
\hline $\begin{array}{l}\text { Self-financing } \% \text { on total } \\
\text { investment }\end{array}$ & $\begin{array}{l}\text { Percentage of overall investment that is financed through } \\
\text { cash flow generated by early deployed units }\end{array}$ \\
\hline $\begin{array}{l}\text { Option value related only to the } \\
\text { second module construction }\end{array}$ & $\begin{array}{l}\text { Advantage, in financial terms, that is linked to the second } \\
\text { unit thanks to modularity }\end{array}$ \\
\hline $\begin{array}{l}\text { Option value related only to the } \\
\text { third module construction }\end{array}$ & $\begin{array}{l}\text { Advantage, in financial terms, that is linked to the third unit } \\
\text { thanks to modularity }\end{array}$ \\
\hline $\begin{array}{l}\text { Overall value of expansion } \\
\text { options }\end{array}$ & $\begin{array}{l}\text { Advantage, in financial terms, that is linked to the nuclear } \\
\text { plant thanks to modularity: 'Option value related only to the } \\
\text { second module construction' + 'Option value related only to } \\
\text { the third module construction' }\end{array}$ \\
\hline
\end{tabular}




\section{Results}

The ENPV model highlights that in the presence of high uncertainty in the external variables, particularly regarding the trend in the electricity price, the expansion options linked to the plant's modularity assume a significant overall value, approximately $€ 8$ million (see Figure 5). If the uncertainty in the price of electricity falls, then the value of the options also decreases.

Figure 5 Overall value of the sequence of expansion options

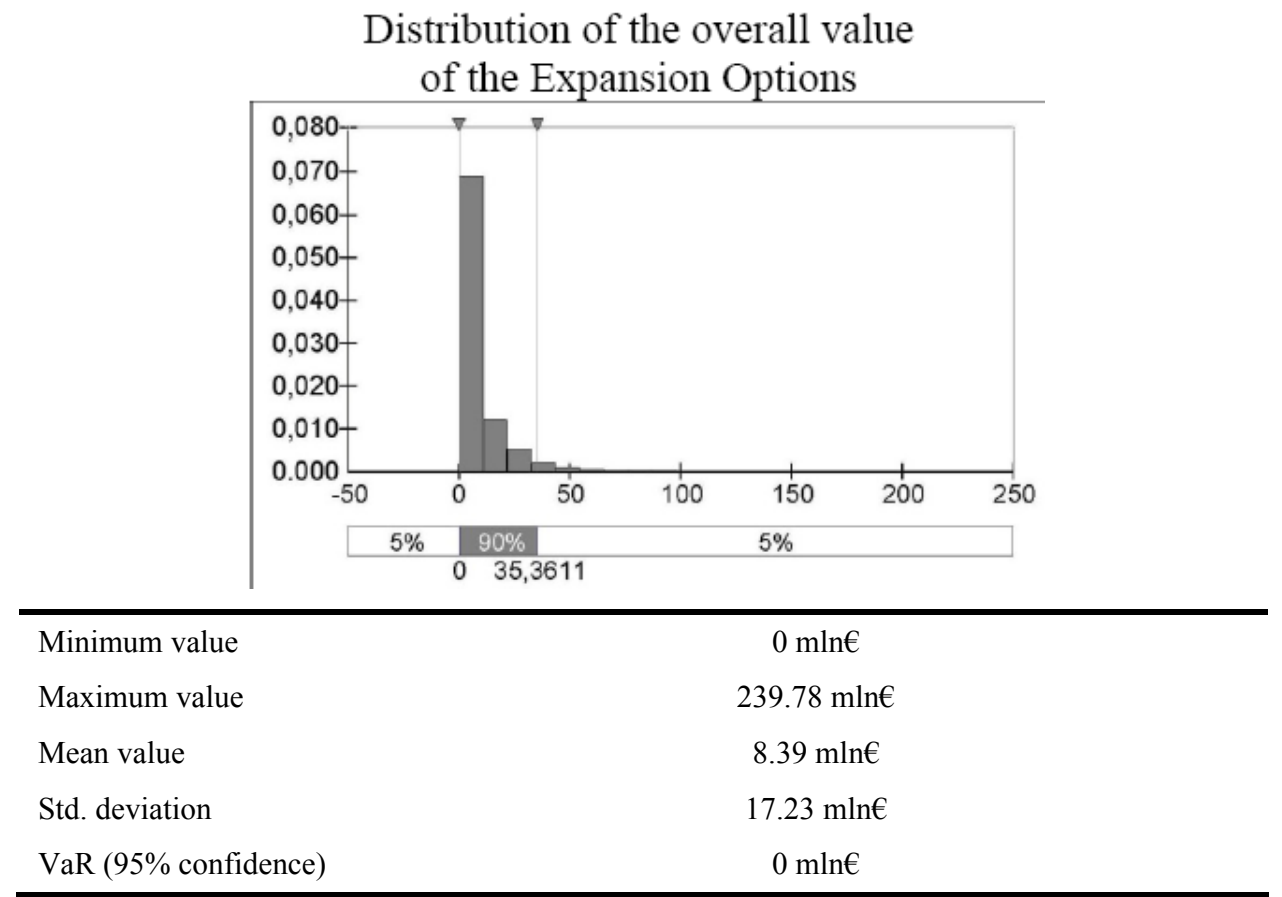

In particular, the overall value of the expansion options can reach very high levels if external conditions are not favourable and the expansion options are not exercised, so avoiding a dramatic project failure.

The first option contributes $81 \%$ and the second $19 \%$ of the overall value of the expansion options, indicating that the value of the options falls as project progresses and uncertainty about the remaining work diminishes.

From the comparison between the NPV distribution of the modular configuration with expansion options and the NPV distribution of the modular configuration without expansion options, it is possible to obtain a more detailed analysis of the two alternatives.

In Figure 6, the difference between maximum values of NPV appears to be negligible. On the contrary, there is a significant difference in the minimum values of NPV, since expansion options may be decisive in limiting project losses in case of nonfavourable contexts. Due to the same reason, also the value at risk (VaR) of the NPV at $95 \%$ confidence level is quite different between the two cases. 
Figure 6 (a) Comparison between the NPV of the modular configuration without expansion options and (b) the NPV of the modular configuration with expansion options

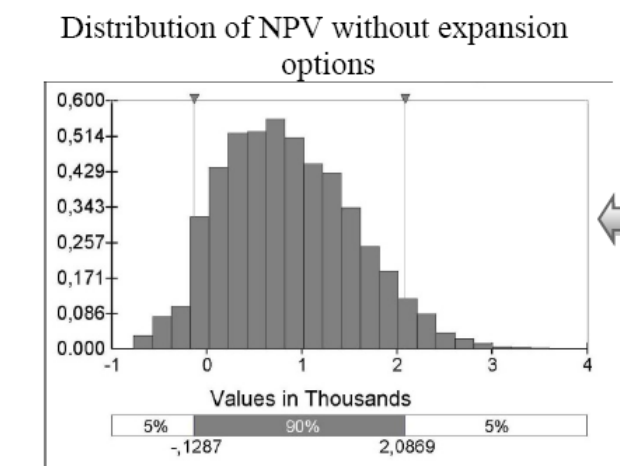

Distribution of NPV with expansion options

\begin{tabular}{lclc}
\hline Minimum value & $-906.15 \mathrm{mln} €$ & Minimum value & $-766.45 \mathrm{mln} €$ \\
Maximum value & $3601.86 \mathrm{mln} €$ & Maximum value & $3,599.37 \mathrm{mln} €$ \\
Mean value & $853.43 \mathrm{mln} €$ & Mean value & $860.07 \mathrm{mln} €$ \\
Std. deviation & $698.23 \mathrm{mln} €$ & Std. deviation & $692.66 \mathrm{mln} €$ \\
VaR $(95 \%$ confidence $)$ & $-176.4 \mathrm{mln} €$ & VaR $(95 \%$ confidence $)$ & $-128.7 \mathrm{mln} €$ \\
\hline
\end{tabular}

(a)

(b)

Figure 7 (a) NPV distribution related to second and third module without expansion options and (b) with expansion options

Distribution of NPV related to SMR 2 and SMR 3 without expansion options

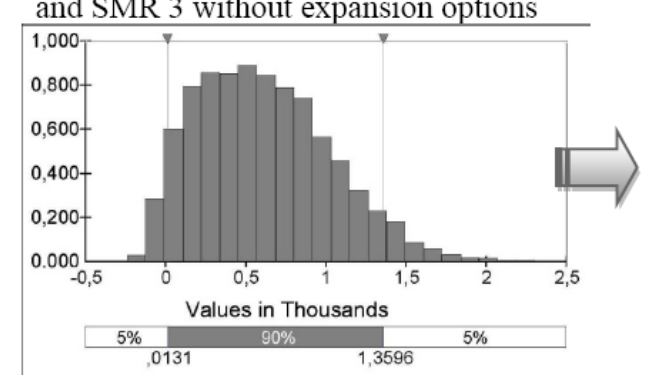

Minimum value $\quad-239.78 \mathrm{mln} €$

Maximum value

Mean value

Std. deviation

VaR (95\% confidence)
Distribution of NPV related to SMR 2 and SMR 3 with expansion options

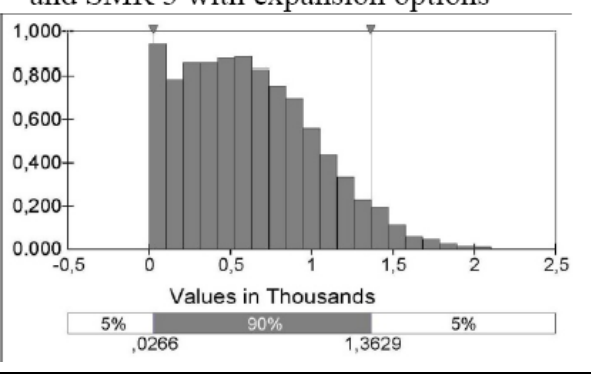

Minimum value $\quad 0$ mln€

Maximum value

2,313.44 mln€

$618.97 \mathrm{mln} €$

$232.16 \mathrm{mln} €$

$26.6 \mathrm{mln} €$

(a)

(b)

It should be noted that determining the NPV distribution related only to the second and third module, since the first has the same impact in both configurations, i.e., with and without options, the expansion options associated to the second and third modules reduce 
significantly the impact of uncertainty on the project performance. Indeed, by postponing and/or possibly cancelling at least partially the investment (i.e., with a proactive role on the part of management), the negative tail of the NPV distribution can be eliminated (see Figure 7), therefore eliminating or at least reducing possible project losses.

On average, $3.17 \%$ of the investment was covered by auto-financing deriving from modules already operating, so reducing the risk exposure for investors.

The main parameters that have an impact on the value of the expansion options are the price of electrical energy and, consequently, the overnight cost, which is correlated to the energy price. These two parameters define, respectively, the cash flow during the operation phase and the initial investment, confirming the analogy with the assessment of financial options based on the comparison between the value of the underlying asset (corresponding to the project cash flow) and the strike price (corresponding to the overnight cost).

Other financial aspects also influence the value of the option, albeit to a lesser extent. The cost of the debt capital, the cost of the equity and the funding mix appear to be particularly relevant.

\section{Conclusions}

A model of the project cash flow has been proposed aiming at the evaluation and comparison of alternative investment projects in the electricity production industry. The model is made up of three sub-models related to construction phase, operation phase and the trend of electricity price respectively. The model focuses in particular on the construction phase, in which the most relevant decisions are taken influencing the subsequent project development, and takes account of the expenditure profile during construction, possible delays, economies of learning, and moreover, possible self-financing.

Based on the above model, an ENPV model has been developed in order to estimate the value of the sequence of expansion options deriving from the plant's modular configuration. The overall value of the expansion options is determined as the difference between the NPV of the modular project with expansion options and the NPV of a similar, modular project without expansion options. In the latter case, the management cannot decide whether and when to invest and therefore there is no project flexibility. However, the proportion of the overall value of the expansion options that can be effectively harnessed depends on management's ability to exploit the greater information that becomes available as the project progresses.

Application of the model to a nuclear power plant reveals that in conditions of high uncertainty of the context variables, expansion options play a significant role, particularly by eliminating possible losses through the postponement or partial cancellation of the investment. Overall, therefore, it is possible to conclude that, in a dynamic and complex context, such as the electricity production industry, plant's modularity - and the corresponding project flexibility - offers significant opportunities.

Further research topics regarding the suggested framework, may add the consideration of the advantages deriving from modularity during the operation phase in terms of availability, service continuity and production elasticity. 


\section{References}

Arrto, K., Kujala, J., Dietrich, P. and Martinsuo, M. (2008) 'What is project strategy?', International Journal of Project Management, Vol. 26, No. 1, pp.4-12.

Arrto, K., Lehtonen, M., Aaltonen, K., Aaltonen, P., Kujala, J., Lindemann, S. and Murtonen, M. (2009) 'Two types of project strategy-empirical illustrations in project risk management', Paper presented at the IRNOP IX Conference, October, Berlin, Germany.

Barraquand, J. and Martineau, D. (1995) 'Numerical valuation of high dimensional multivariate American securities', Journal of Financial and Quantitative Analysis, Vol. 30, No. 3, pp.383-405.

Black, F. and Scholes, M. (1973) 'The pricing of options and corporate liabilities', Journal of Political Economy, Vol. 81, No. 3, pp.637-659.

Blanco, C. and Soronow, D. (2001a) 'Mean reverting process - energy price processes used for derivatives pricing \& risk management', Commodities Now, June, Vol. 4, pp.68-72.

Blanco, C. and Soronow, D. (2001b) 'Jump diffusion processes - energy price processes used for derivatives pricing \& risk management', Commodities Now, September, Vol. 7, pp.83-87.

Blanco, C., Choi, S. and Soronow, D. (2001) 'Energy price process used for derivatives pricing \& risk management', Commodities Now, March, Vol. 1, pp.74-80.

Boarin, S. and Ricotti, M. (2010) 'INCAS integrated model for the competitiveness analysis of small-medium sized reactors', IAEA Internal document.

Brabazon, T. (1999) 'Real options: valuing flexibility in capital investment decisions', Accountancy Ireland, Vol. 31, No. 6, pp.16-18.

Broadie, M. and Detemple, J. (1997a) 'Recent advances in numerical methods for pricing derivative securities', in Rogers, L.C.G. and Talay, D. (Eds.): Numerical Methods in Finance, Cambridge University Press, Cambridge.

Broadie, M. and Detemple, J. (1997b) 'The valuation of American option: valuation on multiple assets', Mathematical Finance, Vol. 7, No. 3, pp.241-286.

Broadie, M. and Glasserman, P. (1995) 'Pricing American-style securities using simulation', Journal of Economic Dynamics and Control, Vol. 21, No. 8, pp.1323-1352.

Broadie, M. and Glasserman, P. (2004) 'A stochastic mesh method for pricing high-dimensional American options', The Journal of Computational Finance, Vol. 7, No. 4, pp.35-72.

Browman, E.H. and Moskowitz, G.T. (2001) 'Real options analysis and strategic decision making', Organization Science, Vol. 12, No. 6, pp.772-777.

Cobb, B.R. and Charnes, J.M. (2007) Real option valuation', Paper Presented at the 2007 Winter Simulation Conference, 9-12 December, Washington DC, USA.

Copeland, T. and Antikarov, V. (2001) Real Options: A Practitioner's Guide, Texere LLC, New York.

Damodaran, A. (2002) Investment Valuation: Tools and Techniques for Determining the Value of any Asset, John Wiley \& Sons, Inc., New York.

Dixit, A.K. and Pindyck, R.S. (1994) Investment under Uncertainty, New Jersey University Press, New Jersey.

Dixit, A.K. and Pindyck, R.S. (2000) 'Expandability, reversibility, and optimal capacity choice', in Brennan, M.J. and Trigeorgis, L. (Eds.): Project Flexibility, Agency, and Competition, pp.50-69, Oxford University Press, Oxford.

Feretic, D. and Tomsic, Z. (2005) 'Probabilistic analysis of electrical energy costs: comparing production cost of gas, coal and nuclear power plants', Energy Policy, Vol. 33, No. 1, pp.5-13.

Floricel, S. and Miller, R. (2001) 'Strategizing for anticipated risks and turbulence in large scale engineering projects', International Journal of Project Management, Vol. 19, No. 8, pp. $445-455$. 
Fraser, P. (2003) Power Generation Investment in Electricity Markets, OECD/IEA Publication, Paris.

Gollier, C., Proult, D., Thais, F. and Walgenwitz, G. (2005) 'Choice of nuclear power investments under price uncertainty: valuing modularity’, Energy Economics, Vol. 27, No. 4, pp.667-685.

Grant, D., Vora, G. and Weeks, D. (1997) 'Path-dependent options: extending the Monte Carlo simulation approach', Management Science, Vol. 43, No. 11, pp.1589-1602.

Hellstrom, M. and Wikstrom, K. (2005) 'Project business concepts based on modularity improved maneuverability through unstable structures', International Journal of Project Management, Vol. 23, No. 5, pp.392-397.

Kester, W.C. (1984) 'Today's options for tomorrow's growth', Harvard Business Review, Vol. 62, pp.153-160.

Kodukula, P.Dr. and Papudesu, C. (2006) Project Valuation Using Real Option - A Practitioner's Guide, J. Ross Publishing, Fort Lauderdale, FL.

Kolltveit, B.J., Karlsen, J.T. and Gronhaug, K. (2004) 'Exploiting opportunities in uncertainty during the early project phase', Journal of Management in Engineering, Vol. 20, No. 4, pp.134-140.

Longstaff, K.J. and Schwartz, E. (2001) 'Valuing American options by simulation: a simple least-squares approach', The Review of Financial Studies, Vol. 14, No. 1, pp.113-147.

Mason, S.P. and Merton, R.C. (1985) 'The role of contingent claims analysis in corporate finance. Recent advance in corporate finance', in Altman, E.I. and Subrahmanyam, M.G. (Eds.): Recent Advances in Corporate Finance, pp.7-54, Irwin, Homewood, IL.

McDonald, R. and Siegel, D. (1984) 'The value of waiting to invest', Quarterly Journal of Economics, Vol. 101, No. 4, pp.707-728.

Merton, R.C. (1973) 'The theory of rational Oprion pricing', Bell Journal of Economics and Management Science, Vol. 4, No. 1, pp.141-183.

Miller, K. (2005) 'IRIS - economic review', Paper presented at the Proc. 13th International Conference on Nuclear Engineering (ICONE-13), 16-20 May, Beijing, China.

Miller, R. and Lessard, D. (2000) The Strategic Management of Large Engineering Projects, Shaping Institutions, Risks and Governance, MIT Press, Cambridge, MA.

Miller, R. and Lessard, D. (2001) 'Understanding and managing risks in large engineering projects', International Journal of Project Management, Vol. 19, No. 8, pp.437-443.

Moel, A. and Tufano, P. (2000) 'Bidding for the antamina mine: valuation and incentives in a real option context', in Brennan, M.J. and Trigeorgis, L. (Eds.): Project Flexibility, Agency, and Competition, pp.128-149, Oxford University Press, Oxford.

Morris, P.W.G. and Jamieson, A. (2005) 'Moving from corporate strategy to project strategy', Project Management Journal, Vol. 36, No. 4, pp.5-18.

Mun, J. (2002) Real Option Analysis, Tools and Techniques for Valuing Strategic Investment and Decisions, John Wiley \& Sons, Inc., Hoboken, New Jersey.

Myers, S.C. (1977) 'Determinants of corporate borrowing', Journal of Financial Economics, Vol. 5, No. 2, pp.147-175.

Myers, S.C. (1984) 'Finance theory and financial strategy', Interfaces, Vol. 14, No. 1, pp.473-487.

O’Sullivan, A. (2003) Economics: Principles in Action, Pearson Prentice Hall, Upper Saddle River, New Jersey.

Olsson, N.O.E. (2006) 'Management of flexibility in projects', International Journal of Project Management, Vol. 24, No. 1, pp.66-74.

Olsson, N.O.E. (2008) 'External and internal flexibility - aligning projects with the business strategy and executing projects efficiently', International Journal of Project Organization and Management, Vol. 1, No. 1, pp.47-64.

Rode, D., Fishbeck, P. and Dean, S. (2001) 'Monte Carlo methods for appraisal and valuation: a case study of a nuclear power plant', Journal of Structured and Project Finance, Vol. 7, No. 3, pp.38-48. 
Roques, F.A., Nuttall, W.J. and Newbery, D.M. (2006) 'Using probabilistic analysis to value generation investments under uncertainty', MIT Institute Report.

Ross, S.A. (1978) 'A simple approach to the valuation of risky income streams', Journal of Business, Vol. 51, No. 3, pp.453-475.

Schwartz, E.S. and Trigeorgis, L. (2004) Real Options and Investment under Uncertainty: Classical Readings and Recent Contributions, MIT Press, Cambridge.

Smith, J.E. (2005) 'Alternative approaches for solving real options problems', Decision Analysis, Vol. 2, No. 2, pp.89-102.

Smith, J.E. and McCardle, K.F. (1998) 'Valuing oil properties: integrating option pricing and decision analysis approaches', Operations Research, Vol. 46, No. 2, pp.198-217.

Trigeorgis, L. (1993) 'The nature of options interactions and the valuation of investments with multiple real options', Journal of Financial and Quantitavive Analysis, Vol. 28, No. 1, pp.1-20.

Trigeorgis, L. (1995) Real Options in Capital Investment: Models, Strategies, and Applications, Greenwood Publishing Group, Portsmouth, NH.

Tseng, C.L. and Barz, G. (2002) 'Short-term generation asset valuation: a real option approach', Operations Research, Vol. 50, No. 2, pp.297-310.

\section{List of main abbreviation and acronyms}

D Debt

D\&D Decommissioning and decontamination

DCF Discounted cash flow

DTA Decision tree analysis

E Equity

ENPV Expanded net present value

GBM Geometric Brownian motion

kd Cost of debt

ke Cost of equity

LR Large reactor

LUEC Levelised unit electricity cost

Mln Million

NPV Net present value

O\&M Operation and maintenance

OFCF Operational free cash flow

PDE Partial differential equations

ROA Real option analysis

SG Steam generator

SGTR Steam generator tube rupture

SMRs Small medium reactors

VaR Value at risk 